JET 4866 (JET 43:1)

\title{
Metaphors Used by Pre-service Teachers of Chinese as an International Language
}

\author{
MA Xiuli ${ }^{\mathrm{a}}$ and GAO Xuesong ${ }^{\mathrm{b} *}$ \\ ${ }^{a}$ Minzu University of China, Beijing, People’s Republic of China \\ ${ }^{\mathrm{b}}$ Faculty of Education, The University of Hong Kong, Hong Kong, SAR
}

* Corresponding author. Email: xsgao@hku.hk 


\begin{abstract}
This inquiry explored 68 pre-service perceptions and aspirations of TCIL (Teaching Chinese as an International Language) teachers by analysing the metaphors they used to describe themselves as teachers. The inquiry revealed that the participants used a variety of metaphors to project the images of themselves as pre-service TCIL teachers. The results also confirm that the participants' use of metaphors, as powerful tools to understand the complexity of teaching, reflects the mediation of cultural, historical and socio-political conditions. These findings help teacher educators to support TCIL teachers' professional development by engaging them in critical dialogues about the metaphors they use to perceive themselves as TCIL teachers. They also help teacher educators to adopt tailor-made pedagogical content to address their development needs.
\end{abstract}

Keywords: Pre-service teachers, Teaching Chinese as an international language, Metaphor, Professional identity

\title{
INTRODUCTION
}

A crucial element of pre-service teacher education is helping student teachers develop appropriate knowledge and beliefs about 'pedagogy and practice', 'students' and 'self' (Santoro 2009, 34). It has been argued that 'learning to be a teacher is as important as learning how to teach’ since pre-service development of teachers’ professional identities profoundly mediates their 'well-being', pedagogical beliefs and practices, 'effectiveness' and career development (Friesen and Besley 2013, 23). This has given rise to research on teachers' pre-service perceptions about themselves and teaching as teachers are expected to assume increasingly complex professional roles in many contexts (e.g. Santoro 2009; Thomas and Beauchamp 2011). These studies have generated significant findings for teacher educators which can better support teachers in 
the process of becoming teachers, including Teaching Chinese as an International Language (TCIL) teachers.

Following the Chinese government's escalated efforts to promote the learning of Chinese language and culture, Chinese language education programmes in and outside mainland China have witnessed unprecedented growth. According to Hanban, the headquarters of Confucius Institutes, there were 1,500 Confucius Institutes and classrooms in 134 countries, employing 34,000 full-time and part-time teaching staff for over 1.90 million students as of December 2015 (Hanban 2016). To respond to this growth many Chinese universities have expanded TCIL teacher education programmes (Hanban 2014; Wang and Adamson 2014). In contrast with the unprecedented expansion of Chinese language education and teacher education programmes, understanding of how pre-service TCIL teachers view themselves and their profession is inadequate. To address this problem, the researchers undertook an inquiry among a selected group of pre-service TCIL teachers in a Chinese university in Beijing to answer the following research question: How do pre-service TCIL teachers see themselves at the beginning of a teacher education programme?

Previous research suggests that 'direct questions about identity tended to elicit responses related to roles one fulfils or activities one engages in, "the what" rather than "the who"' (Thomas and Beauchamp 2011, 764). For this reason, the researchers addressed the question by examining the metaphors that the participants used to understand their experiences since metaphor has been regarded as an important cognitive tool for us to ‘make sense of our lives’ (Lakoff and Johnson 1980, 233). 


\section{METAPHOR AS A LENS TO EXPLORE TEACHERS' PROFESSIONAL THINKING AND COGNITION}

Metaphors have been seen as an important cognitive tool people use to organise their thinking, feelings and experience so that we can make sense of 'most of what we think, experience and do’ (Lakoff and Johnson 1980, 3-5). In teacher education research, metaphors ‘provide useful windows into teachers’ professional thinking and cognition’ and have '10 distinct functions' in teaching and teacher education (Saban 2006, 301). Among the functions reviewed by Saban, metaphor has been used by teacher educators and researchers as 'a blueprint of professional thinking', 'an archetype of professional identity', 'a medium of reflection' and 'a springboard for change' in teachers' professional beliefs. Other studies have noted that teachers widely use metaphors to understand the complexity of teaching, which allows metaphors to serve as 'vehicles for reflection and consciousness raising among educators' (e.g. Guerrero and Villamil 2002, 95). An increasing number of studies have used metaphors to examine the conceptions of teachers, especially pre-service teachers, with regard to learning and teaching (e.g. Guerrero and Villamil 2002; McGrath 2006; Oxford et al. 1998; Shaw and Mahlios 2011). McGrath (2006, 316) contends that 'even one-stage metaphor studies’ of teacher metaphors can help reveal what teachers need and want 'in local contexts' to inform their 'continuing professional development'.

Metaphor has become a particularly useful tool for researchers to explore how preservice teachers perceive 'the self as a professional' during this 'crucial stage in the development of teacher identity' (Thomas and Beauchamp 2011, 762-763; also Saban, 
Kocbeker and Saban 2007). Previous research also suggests that teachers' use of metaphors is not only a cognitive phenomenon but also a sociocultural one that emerges from cognition in interaction with various sociocultural processes and conditions (Guerrero and Villamil 2002; Martínez et al. 2001; Oxford et al. 1998). Therefore, in the context of understanding metaphors used by pre-service TCIL teachers, it is important to appreciate the social and cultural contexts during the emergence of TCIL teachers as a distinct group of language teachers.

\section{TEACHING CHINESE AS AN INTERNATIONAL LANGUAGE}

Pre-service Teaching Chinese as an International Language teachers, if they have grown up in mainland China, get acculturated to beliefs profoundly influenced by the Chinese traditional culture, which assigns enormous importance to the role of education in cultivating moral and intercultural qualities among individuals (Lee 2000). The Chinese tradition emphasises authority of and respect for teachers, but it also imposes high expectations on teachers. For instance, teachers are expected to be experts in the subjects they teach and they are also expected to be morally beyond reproach. If they fail to fulfil these expectations, they are to be censured and criticised by the public. They have also been socialised into certain pedagogical beliefs through learning in particular ways (e.g. repetitive memorisation) as students. For this reason, many TCIL teachers were found in research to have struggled when choosing appropriate pedagogical approaches for teaching (Zhou and Li 2015). In particular, they were criticised for an 'emphasis on drilling, rote-learning and reliance on character teaching, at the expense of communicative oral work’ (Moloney 2013, 215). 
In addition, pre-service TCIL teachers need to tune in socio-political discourses about the Chinese language education because the Chinese government is committed to expanding its soft, ‘cultural’ power (e.g. Hubbert 2014; Wang and Adamson 2014). They are expected to be familiar with traditional Chinese culture in order to promote and disseminate Chinese language and culture in diverse contexts (Zhu et al. 2015). However, the Hanban’s mission to promote Chinese language and culture has not been without setbacks. In recent years, there have been critical censures of Confucius Institutes’ political agenda and reports of closures of Confucius Institutes in some countries have also appeared in newspapers, casting doubts about the future of teaching Chinese as an international language (e.g., Graham 2014; Louie 2011; Wang and Adamson 2014). Negative media coverage on individual Confucius Institutes may undermine pre-service Teaching Chinese as an International Language teachers’ confidence in their careers as it reminds them of the challenges in teaching Chinese as an international language. In light of these noticeable developments, the current study examines how pre-service TCIL teachers perceive themselves as teachers in metaphorical terms.

\section{THE INQUIRY}

This inquiry explored TCIL teachers’ pre-service professional perceptions through analysing the metaphors they use to describe themselves as TCIL teachers in a major university in Beijing, China. At the time of data collection, 8 universities in Beijing offered TCIL-related master's programmes with an annual intake of 328 domestic and 
165 international students. This university is a respectable but non-'elite’ institution and is ranked in the middle of the 8 institutions in terms of reputation and student intake quality. A total of 83 pre-service TCIL teachers were enrolled in this university in the academic year of 2014, including 68 Chinese teachers and 15 foreign teachers who were mostly from Southeast Asia, such as Myanmar, Vietnam and Thailand. In order to minimise the influence of nationality and cultural background, the researchers decided to focus on pre-service TCIL teachers of Chinese nationality only. Metaphors these students used were collected at the beginning of their master's studies to minimise the impact of postgraduate education on the participants' perceptions about themselves as TCIL teachers.

The 68 participants, who voluntarily participated in the study, included 60 female and 8 male students, reflecting the actual gender composition of the TCIL-related programmes. They belonged to programmes including Master of Arts in Chinese linguistics and literature (teaching Chinese to speakers of other languages specialisation) and Master of Education in Teaching Chinese as an international language. Most of the participants had just completed undergraduate studies in Chinese language and literature, or English language and literature, before they started the Masters study. They had no prior teaching experience. Two of them had studied Chinese language education in second-tier universities and had no experience of teaching Chinese as an international language at all. In other words, prior academic studies had limited impact on their envisioning of themselves as TCIL teachers before this inquiry was conducted.

To collect the participants' perceptions in the form of metaphors, the researchers followed Guerrero and Villamil (2002). Students were given open ended questions to 
complete, including ‘Teachers of Chinese as an international language.......'. Before they were asked to answer the question, the researchers explicitly told the students to use metaphors and explained how they could use particular metaphors, if applicable. In the questionnaire, the researchers quoted an English teacher's metaphorical statement in Guerrero and Villamil’s (2002 ) study as an example, “A foreign language teacher is a tree full of apples (metaphor), they possess language knowledge and dispense the knowledge to students (explanation)”. The italics were added by the researchers to illustrate how to complete the sentence beginning with "A TCIL teacher is like...”. The participants were then asked to produce their metaphors in response to the cue "A TCIL teacher is like...” and provide explanations for their own metaphors. Following this activity, face-to-face and email exchanges were undertaken with the participants to obtain further information about their metaphor usage. The participants were told that their identities would be kept confidential and only pseudonyms would be used when reporting on the study.

There are a variety of ways to classify the metaphors teachers use to describe their thinking and experience, including content analysis in which themes or major categories of metaphors were identified and explicated (e.g. Saban et al. 2007). In this study, analysis of the participants' metaphors was undertaken within a grounded theory approach through multiple readings (Birk and Mills 2015). In the first reading, the researchers went through all the data to identify the metaphors first, which led to the identification of 76 metaphors in the data set (see Table 1). In the second reading, the researchers established similarities and differences among the identified metaphors before classifying them into three major categories, professional competencies and attributes, knowledge dissemination and student development (i.e. teachers’ roles in 
student development). 'Professional competencies and attributes' covers the metaphors that participants used to refer to professional knowledge and skills required for teaching Chinese as an international language ('professional competencies'). They also stress the importance of teachers' emotional and volitional characteristics and awareness of professional development ('professional attributes’). 'Knowledge dissemination’ includes both dissemination of language knowledge ('knowledge dissemination') and Chinese culture ('cultural dissemination') in teaching Chinese. The metaphors under 'student development' refer to the roles that the participants felt obliged to play in supporting and guiding students' learning of Chinese. In the analysis, the researchers also identified a small number of metaphors that participants used to denote the low social status of TCIL teachers, such as 'migrant worker', which are highly revealing about their perceptions of themselves as TCIL teachers. Further readings helped the researchers refine the categories of classification and to search for the conceptual connections among the identified metaphors to theorise the participants' metaphor usage (Birk and Mills 2015).

It was noted in the analysis that the same metaphor could be used by participants to convey several intended meanings. For instance, two participants (S4 and S46) referred to 'teachers' as 'mother'. The mother metaphor is indicative of particular qualities that teachers need to have, such as patience, love and care, but it is also about the important role that teachers play in student development. Considering these implied meanings, the researchers decided to classify these into two categories, i.e. professional attributes and student development. A total of 105 metaphorical meanings in the 76 metaphors were identified in the analysis (see Table 1). It is inevitable for individual researchers to have divergent views when classifying data, i.e. particular metaphors. Since the researchers 
asked the participants to explain why they chose particular metaphors, these explanatory notes contributed towards a high inter-rater agreement between the researchers (i.e. 94.3\%). In case of any disagreement, the researchers discussed these metaphors among themselves and requested participants to clarify what they meant through email or faceto-face conversations. Such additional data helped fine tune the classification of metaphors in the analysis.

\section{[Insert Table 1 About Here]}

\section{FINDINGS}

As can be seen in Table 1, the participants generated a large number of metaphors concerning professional competencies and attributes (43.8\%) that they need to acquire before teaching Chinese as an international language. The participants' emphasis on the importance of professional competencies and attributes as essential to their professional identities probably reflects the stage of professional development that they were in during the inquiry. It is noteworthy that the participants also produced a significant number of metaphorical meanings concerning their roles in student development (31.4\%) and relatively smaller numbers of metaphorical meanings on teachers' dissemination of knowledge (8.6\%) and culture (12.4\%). Only a small number of metaphorical meanings were used to reflect awareness of the professional status (3.8\%) but the issues these meanings involve were significant and deserved close attention. For instance, S45 used the metaphor of 'monks' to express uncertainty about the future career of a Chinese teacher since 'many monks were forced to leave monasteries in search for a living.' Other participants used metaphors such as 'grass' (S14) or ‘TV programme migrant 
worker' (S6) to show that the vocation of teaching Chinese as an international language and TCIL teachers has a low social status. 4 metaphors (S6, S14, S38, S45) relating to professional status appeared in the dataset, indicative of the participants' career-related concerns (Hanban 2013). The following three sections of the paper focus on the first five categories of metaphors used by the participants.

\section{Professional competencies and professional attributes}

The participants used 24 metaphors to refer to the professional competencies that they need to become good Chinese teachers and 22 other metaphors to outline the professional attributes of good teachers they aspired to become. A close examination of these metaphors revealed profound mediation of cultural and traditional discourses about teachers on the participants' beliefs regarding what competencies and attributes are required of good teachers. In specific terms, over half of these participants (15) stressed the importance of Chinese teachers mastering all the skills and knowledge needed for teaching Chinese as an international language. The participants believed that teachers need to devote themselves selflessly to teaching and their students, providing them with love, care, knowledge and skills. In support of such endeavours, teachers are expected, by at least four participants, to be knowledgeable, willing to improve teaching and 'emotionally stable'. These findings are illustrated with specific metaphors together with the participants' explanations

The participants used a variety of metaphors associated with popular cultures inside and outside mainland China to show that Chinese teachers need to master a variety of skills and knowledge for teaching, such as Doraemon, Transformer and 
Taobao.com. Some of the metaphors were related to Chinese culture such as chopsticks and Monkey King. Participant S10 used Doraemon, a cartoon figure from Japan, to describe Chinese teachers. Since this cartoon figure is known to possess all techniques and solutions to problems, she explained in the follow-up explanation that TCIL teachers also need to have 'all the know-hows' in their pocket so that they can help students solve any learning problems in the process. This participant's explanation echoes that of another participant (S61) who presented TCIL teachers as Taobao, a popular online shopping website in mainland China where one can find many goods. She claimed that 'TCIL teachers should have anything and everything like the Taobao website' so that she could 'provide all sorts of convenient and reliable services.' The desirable professional skills are apparently in line with the traditional discourses about teachers and teacher-centred teaching, which highlight the teachers' capacity to address different challenges in teaching.

It is important to note that this participant (S61) reflected on being a TCIL teacher in terms of service, a popular conception of 'teaching as serving' among the participants. It seems that these participants did not think of teaching as an easy job and instead, viewed it as full of challenges, for which they feel it necessary to be fully prepared. This probably explains why another participant (S12), who used Transformer to refer to Chinese teachers, believed that a TCIL teacher needs more than professional skills and knowledge:

A teacher needs specialised competencies for teaching the language, needs to understand Chinese culture and have some Chinese artistic talents. She/he must be kind and approachable and also needs to deal with sharp criticism well. She/he needs a strong body like that of an athlete to cope with all sorts of situations energetically. 
As can be inferred from the extract above, this participant also saw herself as a representative of Chinese culture and felt obliged to present Chinese culture when teaching. She was fully aware that teaching is no longer a profession beyond reproach (e.g. Moloney 2013; Zhou and Li 2015). In fact TCIL teachers now need to deal with difficult pedagogical situations and face critical evaluations of their teaching. For this reason other participants stressed that TCIL teachers need a variety of professional competencies and qualities. For example, participant S27 used the metaphor of 'surgeon 'to suggest that a teacher needs to learn to provide solutions to students after diagnosing their learning problems properly. The metaphor of 'I-phone' was used by participant S43 to stress the importance of innovative teaching for TCIL teachers while participant S25 used 'Chef' to indicate that teachers need the relevant professional skills to 'transform language materials into delicious meals for the world.' Similarly, participant S64 used the metaphor of 'beautiful sunshine to mean that TCIL teachers should enlighten students by colourfully radiating Chinese language knowledge.

As mentioned earlier, a large number of participants used metaphors suggesting that Chinese teachers should commit themselves to teaching selflessly, echoing the construction of teaching as a selfless vocation in the Chinese cultural tradition (e.g. Lee 2002). These metaphors include 'farmers', ‘leaf', ‘mother', ‘brick', ‘sunshine’ and 'grass'. At least three participants used the metaphor of 'farmer' to indicate that as TCIL teachers they should 'work very hard' (S54) to 'take good care of trees according to their species, farming conditions and usage’ (S60). TCIL teachers are also believed to be like 'sunshine' who 'selflessly bathe students with love and care' (S26) or 'a running clock hand', who 'tirelessly teaches all he or she knows to students' (S52). Participant S44 believed that a good TCIL teacher was like a common but modest 'leaf' who 'relies 
on its limited youth to make unlimited contributions' while participant S45 asserted that a good TCIL teacher should be like a 'brick', which can be 'used to build buildings for promoting the Chinese language'. These metaphors echo what the Chinese tradition and contemporary propaganda expect teachers to be like.

Apart from being selfless teachers who are ready to sacrifice themselves, the participants also noted that TCIL teachers need to be fully prepared for the challenging task of teaching Chinese. To this end, the teacher should be like 'a machine operator', who 'reads manuals and is also ready for innovation' (S8), an 'experienced and wise captain', who 'calmly responds to wild winds, stormy weather and icebergs... in leading us to move forward in the right direction’ (S15). In addition, one participant, who was fully appreciative of the importance of the profession, believed that TCIL teachers were 'miniature of China, who need to be 'highly enthusiastic and determined .... As key players in promoting the Chinese language and culture, they must fully love their own country before they can influence others with this love' (S67). Such metaphor usage reflects the mediation of the wider socio-political discourses about China and the increasingly complex conditions for TCIL teachers to promote Chinese culture on the participants’ perceptions (e.g. Hubbert 2014; Wang and Adamson 2014).

\section{Student development}

As noted earlier, competencies and attributes the participants associated with TCIL teachers are not only closely related to the kind of teachers they aspired to become but they also speak for the participants' awareness of their professional roles in prospective students’ learning process (e.g. McGrath 2006; Shaw and Mahlios 2011). As reflected 
in the metaphors they used to describe TCIL teachers, the participants believed that TCIL teachers play a number of significant roles in students’ language learning and development. While these metaphors still stress the crucial roles that TCIL teachers have, they also indicate that these participants displayed pedagogical beliefs different from those associated with teacher-centred teaching (e.g. Moloney 2013; Zhou and Li 2015). In specific terms, twelve of them articulated that they should guide language learners’ development by using metaphors including 'lighthouse’ (S16), ‘compass’ (S21, 25), ‘captains' (S17, 24), ‘tourist guide’ (S34) and 'helmsman’ or 'navigator' (S41, 47). In addition, 18 participants used metaphors to refer to a variety of supportive roles that a Chinese teacher can have in facilitating students' learning and responding to learning challenges strategically, including 'gigantic cruise ship' (S35) and 'walking stick' (S11).

Among all the roles that the participants believed they should play, the role of 'guiding' was found to be so popular among the participants that the researchers felt the need to discuss it separately (e.g. McGrath 2006). For instance, participant S47 believed that language teachers should 'guide them to develop proper learning approaches' as navigators while another participant (S41) stressed the importance of 'motivating students’ learning by adopting a variety of pedagogical activities and arrangements.' Two participants were certain that teachers should be experienced captains who 'guide students in their exploration of the ocean of knowledge' (S24). Two other participants said they would like to function as a 'compass' to direct students' learning (S21 and 25). Similarly, participant (S16) declared that language teachers are lighthouses that 'guide students into the ocean of knowledge and enlighten them with the directions' 
while participant S34 asserted that language teachers are 'tourist guides' who 'would do their best to take you to the places you want to visit.'

As for the variety of supportive roles that TCIL teachers play in the language learning process, at least four had connotations of teachers being the carriers of learners and the learning process, echoing similar previous findings concerning teachers' roles in supporting students' learning adventures (e.g. Shaw and Mahlios 2011). For instance, participant S2 claimed that 'teachers and students are like water and fish because they provide the environment for students to grow up’ while participant S33 saw TCIL teachers as 'boats....that take individual students to a brand new world' or a cruise ship that 'travels towards an aged civilisation' (S35). Participant S68 further argued that 'TCIL teachers are like wind that supports kites flying. We may be strong or soft wind but we make sure that kites fly farther and higher steadily.' Two other participants stressed that Chinese teachers support students' learning as 'steps' (S8) or 'walking sticks’ (S11). Both metaphors indicate that Chinese teachers should work primarily to help 'climbers walk upward to the peak' (S11). They reflect the participants' awareness of learning Chinese as a difficult uphill battle for many language learners and for this reason teachers should do their best to make it easier for them by providing accessible learning paths. As mentioned earlier, a few participants believed that teachers should act like 'mothers' who take care of their learners with love or 'sunshine' who cheer up language learners in the process (e.g. S4, S46, S64 \& S66).

In contrast to the caring and loving roles mentioned above, a very small number (2) of participants highlighted the disciplinary roles that teachers have to play in students' learning process, showing the influences of teacher-centred teaching on their 
perceptions of themselves as TCIL teachers (e.g. McGrath 2006; Shaw and Mahlios 2011). Participant S5 said that TCIL teachers are like 'animal trainers who make sure 'students keep doing language drills so that they can learn the relevant language skills.' Another participant (S60) argued that language teachers should start teaching students when they start learning Chinese. If they have learnt Chinese from other teachers and have not been taught properly, it becomes difficult for her to teach them because 'fruit trees that grew up elsewhere might have had a lot of unnecessary branches, which should have been pruned' (S60). She believed that language teachers should discipline their students into proper learning just like the farmers should 'prune' trees' branches.

At least three participants presented their roles as something more functional than affective (i.e. 'mother'). Participant S22 used 'chopstick', the most important tool in a Chinese meal, to mean that 'TCIL teachers are the most important mediating persons and assistants for foreign students to learn Chinese.' Similarly, Participant S58 used 'matchmaker' to capture the roles that TCIL teachers play in students' learning process because 'matchmakers usually leave the scene after the students are familiar with the language environment.' Her use of metaphor echoes another participant's (S18) use of 'water melon in the summer', a unique metaphor to capture the involvement of teachers in students' learning. Referring to the process as 'water melon in summer', this participant argued that teachers should gradually reduce their involvement in students' learning process since the first taste of 'water melon' in summer is terrific but one finds water melon tasteless after eating a huge amount of it. This means that teachers' involvement in students' learning process may be appreciated in the beginning but it may not be so afterwards. The participants' explanation of these metaphors offers further insights into the roles that they believed a TCIL teacher should play in the 
language learning process. It seems that the participants might have been aware of the criticisms about Chinese language teachers’ pedagogical approaches in many contexts (e.g. Moloney 2013; Zhou and Li 2015). They also indicated that they were well aware of the objectives that they would need to guide language learners to achieve.

\section{Dissemination of knowledge and culture}

Analysis of the data revealed that the participants had two objectives in their mind when teaching Chinese as an international language, echooing what is required of TCIL teachers in the official document mentioned at the beginning of this paper (i.e., Chinese language and culture dissemination - e.g. Zhu et al. 2015). Thirteen participants were found to have used a variety of metaphors to show that they were committed to disseminating Chinese culture through teaching Chinese in different parts of the world. Among them, 10 participants highlighted TCIL teachers as being messengers spreading Chinese culture and reaching out to different corners of the world. Three others stressed that teachers themselves were the embodiments of key elements of the Chinese culture. In addition, nine participants emphasised that TCIL teachers should focus on transmitting the relevant Chinese knowledge and skills to language learners like a 'martial arts master' (S49) or 'a master chef' (S63).

The participants saw themselves and TCIL teachers as messengers who spread the messages of peace and promote Chinese culture (e.g. Hanban 2014). For this reason, four participants (S23, S30, S42 and S53) wanted to greet the world with Chinese culture in teaching. In particular, participant S42 wanted to promote 'the culture of harmony' in the world. Participant S53 displayed a strong sense of mission for 
achieving the objective of cultural dissemination in the course of teaching. He portrayed a Chinese teacher as 'a messenger for promoting Chinese culture' who is 'charged with a mission to strengthen the connection and exchanges between China and other countries.' Participant (S51) associated the teaching of Chinese language with religious missions, suggesting that commitment is crucial to realisation of missionary objectives. As mentioned earlier, this participant even described such a sense of mission as one of the key professional attributes of being a Chinese teacher. Likewise, participant S50 declared that TCIL teachers are 'bridges....that help Chinese culture to interact with other cultures in the world.' For this reason, other participants believed that it is important for TCIL teachers to embody the Chinese culture that they are expected to promote. Participant S26 pointed out that TCIL teachers are like 'a beautiful Chinese dress', which 'displays the brilliance and elegance of Chinese culture to people in other countries.'

While these participants contended that TCIL teachers play a crucial role in promoting Chinese culture, they were also committed to the dissemination of Chinese language knowledge and skills. For example, participant S49 presented TCIL teachers as a 'martial arts master who has completed studies and is able to take disciples.' In his view, this martial arts master has 'learnt all the skills and is ready to teach these skills to others so that they can disseminate the relevant skills and knowledge' among language learners. The use of metaphors such as 'martial arts master' (S49), or 'sunshine' (S1) or 'mother' (S4) stresses the importance of teachers' pedagogical efforts in supporting language learners' development and is indicative of influence of teacher-centred learning and teaching in their pedagogical beliefs (e.g. Moloney 2013; Zhou and Li 2015). Participant (S63) believed that it is important for Chinese teachers to pass on 
‘cooking expertise’ or communicative competence in Chinese to students when teaching though students, like student chefs, need to 'practice what they have learnt from the teacher' more and reflect on their practice' in the learning process. Such metaphor use highlights the importance of language learners' autonomous learning efforts in their language development.

\section{DISCUSSION}

This inquiry revealed that the participants used metaphors to display perceptions of themselves as pre-service TCIL teachers not only in terms of 'roles one fulfils or activities one engages in' ("the what”), but also the aspirations they had about 'the self as a professional' (“the who”) (Thomas and Beauchamp 2011, 762-764). The roles that the participants aspired to play in students' learning as TCIL teachers echo those reported in previous research (e.g. McGrath 2006; Shaw and Mahlios 2011). As an example, the participants referred to their nurturing roles in students' learning and viewed teaching Chinese as an international language in terms of 'exploration and adventure’ (e.g. by seeing themselves as ‘an experienced and wise captain’), echoing Shaw and Mahlios' (2011) findings on pre-service literacy teachers. The kind of teachers the participants foresaw themselves as being speaks for the complexity of teaching in their perceptions (see also McGrath 2006; Thomas and Beauchamp 2011). In addition, the participants' metaphors, many of which are unique to the teaching of Chinese as an international language, reveal the interaction of cultural, historical and socio-political conditions underlying their perceptions (e.g. Guerrero and Villamil 2002; Oxford et al. 1998). 
According to the Chinese cultural traditions teachers are expected to do their best to serve students in the learning process by providing the required knowledge and skills and guiding the learning as reflected by the participants' use of metaphors including 'mother' and 'farmer' (e.g. Lee 2002). To achieve these roles, the participants aspired to acquire these professional competencies and attributes as indicated by metaphors like 'Doraemon', 'Transformer' and 'I-phone' for the challenges ahead. In addition, the participants expected themselves, and were expected by the Chinese government, to fulfil the role of messengers in teaching and promoting Chinese culture (see the participants' use of 'pigeon' and 'messenger') (Hanban 2014). The diversity of metaphors used by the participants mirrors the increasingly complex task of teaching Chinese as an international language for pre-service TCIL teachers to assume when asserting their professional identities. In specific terms, they referred to 'criticism' in the metaphors they use to describe what teachers should be able to do (e.g. Graham 2014; Louie 2011).

Since the pre-service teacher education programmes can potentially change teachers' beliefs and mediate their professional development, it is crucial for teacher educators to engage with these pre-service teachers in exploring the important question as to what it means to be a teacher through metaphor use. For instance, teacher educators may use the identified metaphors to open 'dialogues on different theories of teaching and learning' among them (Saban 2006, 312) or 'raising instinctive feelings to the level of consciousness' for reflection and exploration (McGrath 2006, 314). Through critically analysing their metaphor use, pre-service teachers can reflect on 'their personal values, beliefs, philosophies about teaching, learning and schooling' 
while they are 'helped to better understand their professional roles and identities (Saban 2006, 312). By undertaking such reflection and dialogues on these metaphors, preservice teachers may be encouraged to become aware of their own pedagogical beliefs, ‘which may lead to changes in attitudes and practices' (Shaw and Mahlios 2011, 89). For instance, the participants in this inquiry can be encouraged to reflect on and discuss how they can reconcile contradictory roles such as 'animal trainer' (S5) and 'mother' (S4) in supporting language learners’ development.

Such reflection and discussion may help address the limitations observed in research on TCIL teachers’ pedagogical approaches (e.g. Moloney 2013). In addition, the use of metaphors allows teachers to articulate their concerns and expectations in a highly accessible but in-depth manner (e.g. McGrath 2006; Shaw and Mahlios 2011; Thomas and Beauchamp 2011). Previous research suggests that teacher educators can promote ‘a needs-driven, responsive and empowering pedagogy’ by eliciting teachers’ beliefs through metaphor use (e.g., McGrath 2006; Shaw and Mahlios 2011). In the case of pre-service TCIL teachers in the inquiry, the participants might be aware that their prospective students are likely from different cultures which may never have had a teacher-revering tradition. They realized that it would be highly challenging for them to establish an effective and supportive teacher-student relationship in teaching (Zhou and Li 2015). In response (and with Moloney 2013), teacher educators need to integrate the promotion of intercultural communicative competence and cross-cultural awareness in the related TCIL programmes so that TCIL teachers can fulfil their professional roles. 


\section{CONCLUSION}

The study has identified a variety of metaphors that pre-service TCIL teachers use to describe themselves as TCIL teachers. It must be noted that the study only involved a small number of participants at the beginning of their TCIL programme studies. The use of metaphors as a research tool to explore pre-service teachers’ perceptions and beliefs is also constrained by a variety of methodological limitations including the length of participants' writing and details provided in such writing (McGrath 2006). Nevertheless, the study generated important baseline information about pre-service TCIL teachers’ perceptions so that teacher educators can adopt an 'airing and sharing approach' to support pre-service teachers’ professional growth (e.g. ibid. 314).

Since the participants in this inquiry are all Chinese who grew up in mainland China, it is important to explore the professional beliefs and professional identities of TCIL teachers who are not ethnic Chinese or who grow up in non-Chinese contexts. Comparative studies may better inform teacher educators' efforts to promote crosscultural awareness by engaging pre-service TCIL teachers in exploratory discussions concerning 'their professional identities as part of an effective approach for preparing them for the complex and demanding profession they have chosen' (Thomas and Beauchamp 2011, 769). To conclude, further research is needed to explore the use of metaphors by teachers so that related pedagogic efforts can meet their aspirations and promote the professionalism of TCIL teachers. 


\section{REFERENCES}

Birk, M., and J. Mills. 2015. Grounded theory: A practical guide. London: Sage Publications.

Friesen, M. D., and S. C. Besley. 2013. Teacher identity development in the first year of teacher education: A developmental and social psychological perspective. Teaching and Teacher Education 36: 23-32.

Graham, E. J. 2014. Confucius Institutes threaten academic freedom. Academe 100, no. 5: 4-5.

de Guerrero, M. C. M., and O.S. Villamil. 2002. Metaphorical conceptualizations of ESL teaching and learning. Language Teaching Research 6, no. 2: 95-120.

Hanban. 2013. Case compilation of volunteer Chinese language Teachers. Beijing: Higher Education Press.

Hanban. 2014. Confucius Institute annual development report. Beijing, Hanban. http://www.hanban.edu.cn/report/pdf/2014.pdf (accessed on April 18 ${ }^{\text {th }}, 2015$ ).

Hanban. 2016. 孔子学院总数达 500 所 遍布 134 个国家和地区.

http://www.hanban.edu.cn/article/2015-12/05/content_626219.htm (accessed on Jan. 14 $\left.{ }^{\text {th }}, 2016\right)$.

Hubbert, J. 2014. Ambiguous states: Confucius Institutes and Chinese soft power in the U.S. classroom. Political and Legal Anthropology Review 37, no. 2: 329-49.

Lee, H. C. 2000. Education in traditional China: A history. Leiden: Brill.

Louie, K. 2011. Confucius the Chameleon: Dubious Envoy for “Brand China”. Boundary 2 38, no. 1: 77-100.

McGrath, I. 2006. Using insights from teachers’ metaphors. Journal of Education for Teaching 32, no. 3: 303-17.

Moloney, R. A. (2013). Providing a bridge to intercultural pedagogy for native speaker teachers of Chinese in Australia. Language, Culture and Curriculum 26, no. 3 : 213-28.

Oxford, R.L., S. Tomlinson, A. Barcelos, C. Harrington, R. Z. Lavine, A. Saleh, and A. Longhini. 1998. Clashing metaphors about classroom teachers: Toward a systematic typology for the language teaching. System 26: 3-50.

Saban, A. 2006. Functions of metaphor in teaching and teacher education: A review essay. Teaching Education 17, no. 4: 299-315. 
Saban, A., B. N. Kocbeker, and A. Saban. 2007. Prospective teachers' conceptions of teaching and learning revealed through metaphor analysis. Learning and Instruction 17, no. 2: 123-39.

Santoro, N. (2009). Teaching in culturally diverse contexts: What knowledge about 'self' and 'others' do teachers need?. Journal of Education for Teaching 35, no. 1: 33-45.

Shaw, D. M. and M. Mahlios. 2011. Literacy metaphors of pre-service teachers: Do they change after instruction? Which metaphors are stable? How do they connect to theories? Journal of Education for Teaching 37, no. 1: 77-92.

Thomas, L. and C. Beauchamp. 2011. Understanding new teachers’ professional identities through metaphor. Teaching and Teacher Education 27, no. 4: 762-69.

Wang, D. and B. Adamson. 2014. War and peace: Perceptions of Confucius Institute in China and USA. The Asia-Pacific Education Researcher 24, no. 1: 225-34.

Zhou, W. and G. Li. 2015. Chinese language teachers' expectations and perceptions of American students' behavior: Exploring the nexus of cultural differences and classroom management. System 49: 17-27.

Zhu, Y., X. Ma, H. Liu, and J. Zhang. 2015. The Syllabus Analysis of Chinese as International Language Teacher Certificate. Beijing: People’s Education Press. 


\section{TABLES}

Table 1. Metaphors used by the participants $(n=105)$.

\begin{tabular}{|c|c|c|c|c|c|c|}
\hline Category & $\begin{array}{l}\text { Professional } \\
\text { Competencies }\end{array}$ & $\begin{array}{l}\text { Professional } \\
\text { Attributes }\end{array}$ & $\begin{array}{l}\begin{array}{l}\text { Student } \\
\text { development }\end{array} \\
\end{array}$ & $\begin{array}{l}\text { Cultural } \\
\text { Dissemination }\end{array}$ & $\begin{array}{l}\text { Knowledge } \\
\text { dissemination }\end{array}$ & $\begin{array}{l}\text { Professional } \\
\text { Status } \\
\end{array}$ \\
\hline Percentage & $24(22.9 \%)$ & $22(20.9 \%)$ & $33(31.4 \%)$ & $13(12.4 \%)$ & 9 (8.6\%) & $4(3.8 \%)$ \\
\hline $\begin{array}{l}\text { Sample } \\
\text { metaphors }\end{array}$ & $\begin{array}{l}\text { A TV } \\
\text { programme } \\
\text { migrant worker } \\
\text { (S6), a pilot } \\
\text { (S9), } \\
\text { Doraemon } \\
\text { (S11), } \\
\text { Transformer } \\
\text { (S12), } \\
\text { Tea leaf (S20), } \\
\text { a paint brush } \\
\text { (S26) }\end{array}$ & $\begin{array}{l}\text { A machine } \\
\text { operator } \\
\text { (S8),An } \\
\text { experienced } \\
\text { and wise } \\
\text { captain } \\
\text { (S15), } \\
\text { Grass (S14), } \\
\text { Miniature of } \\
\text { China (S67), } \\
\text { Monkey King } \\
\text { (S57) }\end{array}$ & $\begin{array}{l}\text { Water (S2), a } \\
\text { boat (S33), } \\
\text { Mother (S4, } \\
\text { S46), } \\
\text { beautiful } \\
\text { sunshine } \\
\text { (S64), } \\
\text { A travel } \\
\text { guide (S34), } \\
\text { pirate ship } \\
\text { captain (S17) }\end{array}$ & $\begin{array}{l}\text { Dandelion that } \\
\text { flies across the } \\
\text { ocean (S19), a } \\
\text { pigeon (S23), } \\
\text { miniature of } \\
\text { China (S67) }\end{array}$ & $\begin{array}{l}\text { Morning } \\
\text { sunshine (S1), } \\
\text { navigator (S3), } \\
\text { a master chef } \\
\text { who trains } \\
\text { chefs (S63) }\end{array}$ & $\begin{array}{l}\text { Monks (S45) } \\
\text { grass (S14) } \\
\text { TV } \\
\text { programme } \\
\text { migrant } \\
\text { worker (S6) }\end{array}$ \\
\hline
\end{tabular}

